\title{
Persistence of Multiple Paramyxoviruses in a Closed Captive Colony of Fruit Bats (Eidolon helvum)
}

\author{
Louise Gibson ${ }^{1, *, \dagger}$, Maria Puig Ribas ${ }^{1,2,+}{ }^{,}$James Kemp ${ }^{1} \oplus$, Olivier Restif ${ }^{3}$, Richard D. Suu-Ire ${ }^{4}$, \\ James L. N. Wood ${ }^{3}$ and Andrew A. Cunningham 1,2,*id \\ 1 Institute of Zoology, Zoological Society of London, Regent's Park, London NW1 4RY, UK; \\ mariapuigribas@gmail.com (M.P.R.); jamesrussellkemp@gmail.com (J.K.) \\ 2 Royal Veterinary College, University of London, Royal College Street, London NW1 0TU, UK \\ 3 Disease Dynamics Unit, Department of Veterinary Medicine, University of Cambridge, \\ Cambridge CB3 0ES, UK; or226@cam.ac.uk (O.R.); jlnw2@cam.ac.uk (J.L.N.W.) \\ 4 School of Veterinary Medicine, College of Basic and Applied Sciences, University of Ghana, Legon, \\ Accra P.O. Box LG 25, Ghana; suuire@gmail.com \\ * Correspondence: louise.gibson@ioz.ac.uk (L.G.); a.cunningham@ioz.ac.uk (A.A.C.) \\ + These authors contributed equally to this work.
}

check for

updates

Citation: Gibson, L.; Ribas, M.P.; Kemp, J.; Restif, O.; Suu-Ire, R.D.; Wood, J.L.N.; Cunningham, A.A. Persistence of Multiple Paramyxoviruses in a Closed Captive Colony of Fruit Bats (Eidolon helvum). Viruses 2021, 13, 1659. https://doi.org/10.3390/v13081659

\section{Academic Editors: Paola}

De Benedictis, Wanda Markotter and Stefania Leopardi

\section{Received: 19 July 2021}

Accepted: 16 August 2021

Published: 20 August 2021

Publisher's Note: MDPI stays neutral with regard to jurisdictional claims in published maps and institutional affiliations.

Copyright: (c) 2021 by the authors. Licensee MDPI, Basel, Switzerland. This article is an open access article distributed under the terms and conditions of the Creative Commons Attribution (CC BY) license (https:// creativecommons.org/licenses/by/ $4.0 /)$.

\begin{abstract}
Bats have been identified as the natural hosts of several emerging zoonotic viruses, including paramyxoviruses, such as Hendra and Nipah viruses, that can cause fatal disease in humans. Recently, African fruit bats with populations that roost in or near urban areas have been shown to harbour a great diversity of paramyxoviruses, posing potential spillover risks to public health. Understanding the circulation of these viruses in their reservoir populations is essential to predict and prevent future emerging diseases. Here, we identify a high incidence of multiple paramyxoviruses in urine samples collected from a closed captive colony of circa 115 straw-coloured fruit bats (Eidolon helvum). The sequences detected have high nucleotide identities with those derived from free ranging African fruit bats and form phylogenetic clusters with the Henipavirus genus, Pararubulavirus genus and other unclassified paramyxoviruses. As this colony had been closed for 5 years prior to this study, these results indicate that within-host paramyxoviral persistence underlies the role of bats as reservoirs of these viruses.
\end{abstract}

Keywords: chiroptera; Pteropodidae; longitudinal study; Henipavirus; Pararubulavirus

\section{Introduction}

Most emerging infectious diseases presenting threats to public health are zoonoses originating in wildlife [1]. Understanding the ecology of zoonotic, or potentially zoonotic, viruses in their natural hosts is essential to predict and prevent disease emergence [2]. Natural hosts of an infectious agent are those that have co-evolved with the pathogen and are infected in nature without human intervention [3]. Several studies have identified bats as the most likely natural hosts for multiple emerging zoonotic viruses with high case fatality rates, such as SARS-like coronaviruses, Ebola and Marburg filoviruses, lyssaviruses and a range of paramyxoviruses (PVs) [3-5]. It has been hypothesised that bats share unique traits that enhance their potential as viral reservoirs such as long lifespans, large population sizes, high spatial mobility and high sympatry, which provides opportunities for pathogen persistence and for intra- and interspecific transmission of infectious agents $[6,7]$.

Within the Paramyxoviridae, viruses in the Orthoparamyxovirinae and Rubulavirinae subfamilies have been detected in bats, and some of these have been associated with serious emerging zoonotic diseases [8]. Hendra and Nipah viruses (genus Henipavirus) were first detected in the 1990s after severe outbreaks of disease in domestic animals and humans. Hendra virus $(\mathrm{HeV})$ was identified in Australia in 1994 causing fatal pneumonia and encephalitis in horses and humans [8]. Several variants of HeV were found to be 
widespread in Australian fruit bats (Pteropus spp.) and outbreaks of disease have occurred almost every year since its identification [9]. Nipah virus (NiV) emerged in Malaysia in 1998 causing fatal respiratory disease and encephalitis in pigs and humans [10]. Similarly, $\mathrm{NiV}$ was later detected in fruit bats (Pteropus spp.) in Malaysia and, subsequently, from pteropid bats elsewhere in South and Southeast Asia. Nipah virus continues to cause recurrent disease outbreaks in Bangladesh with proved bat-to-human and human-to-human transmission [11,12]. Therefore, fruit bats of the genus Pteropus are widely recognised as the natural reservoirs for $\mathrm{HeV}$ and $\mathrm{NiV}$ and their distribution was assumed to limit the range of henipaviruses [13].

Following $\mathrm{HeV}$ and $\mathrm{NiV}$ emergence, enhanced surveillance for potential pathogens associated with bats led to the discovery of a greater diversity of PVs in these taxa [14-19]. In 2008, henipavirus antibodies were found in the straw-coloured fruit bat (Eidolon helvum), a species of pteropodid bat, in Ghana without sympatry with the suspected Pteropus reservoirs [20]. Subsequent studies have detected several henipa-like virus sequences in faeces, urine and tissues of E. helvum and other African fruit bats [14,15,18]. Although the isolation and culture of African henipaviruses have not yet been achieved, a full genome sequence was obtained from E. helvum in Ghana, confirming its classification within the genus Henipavirus [14,21,22]. Despite evidence of African henipavirus spillover into humans [23], the potential to cause disease is unclear.

In addition, bat PVs in the subfamily Rubulavirinae have been recently discovered with unknown consequences for human or animal health. Menangle virus was isolated in Australia after an outbreak of reproductive disease in pigs, being later detected in humans with a febrile illness and in apparently healthy Pteropus sp. fruit bats [24]. Tioman virus was identified in Malaysian fruit bats with evidence of spillover to humans [25]. Furthermore, in 2008, three pararubulaviruses, or Tuhoko viruses, were isolated from fruit bat faeces in China [26], while three pararubulaviruses, Achimota pararubulavirus 1, 2 and 3 (AchPV1, AchPV2 and AchPV3), have been recently described in an urban population of E. helvum in Ghana [19,27]. There is widespread seropositivity to AchPV1 and to AchPV2 in E. helvum across sub-Saharan Africa, while antibodies to AchPV2 have been detected in people in Ghana [19]. While the clinical implications of zoonotic infection are unknown, experimental infections of ferrets with AchPV1 and AchPV2 were associated with respiratory disease [28].

Eidolon helvum is widely distributed throughout sub-Saharan Africa and it is the bat species most hunted for bushmeat in West Africa [29]. This species frequently forms large colonies in urban areas such as one that roosts in central Accra, Ghana containing up to one million individuals. The circulation of multiple PVs, including henipaviruses and pararubulaviruses, has been confirmed in this large urban population $[14,15,19,30]$. In January 2010, bats caught from the Accra colony were used to establish a closed captive colony of E. helvum in the vicinity of Accra Zoo with mesh double-walls, ground-level cladding and a solid roof to preclude direct or indirect contact with wild bats or other animals [31]. The captive colony was established with 77 bats of mixed age and sex and has been breeding successfully ever since. By April 2015, the colony had reached approximately 115 individuals through births only. Serological studies using a multiplexed microsphere assay demonstrated the presence of antibodies against henipaviruses in the colony over 24 months since the colony was closed, with evidence of maternal antibodies and later seroconversion in juveniles [31]. Additionally, using a NiV antibody binding assay, antibodies were detected from 2009 to 2017 with an average seroprevalence of $60.5 \%$ [32,33]. Longitudinal seroepidemiology shows indirect evidence for PV transmission within the colony [33], but virus detection had not been attempted to date. In this study, we aim to detect and characterise the PVs circulating in the E. helvum captive colony, using under-roost urine samples. The molecular examination of urine samples has been shown to be an effective way of detecting a range of PVs, including henipaviruses, excreted by fruit bats, including E. helvum [15,34]. 


\section{Materials and Methods}

Urine pools $(n=128)$ were collected from the closed captive colony of E. helvum in Accra Zoo over 23 time points from April to July 2015. Plastic sheets were suspended beneath the roosting area inside the bat enclosure (Figure 1) before feeding time, circa 4.00 p.m. Urine pools were collected the following morning circa 6.30 a.m. Urine pools visibly contaminated with faecal or plant material or diluted after heavy rain were not collected, but faecal contamination of samples could not be ruled out. A urine sample comprised of $500 \mu \mathrm{L}$ of the urine pool preserved in $500 \mu \mathrm{L}$ RNAlater (Invitrogen, Waltham, MA, USA). Urine samples were stored at $-80{ }^{\circ} \mathrm{C}$ within $3 \mathrm{~h}$ of collection. At the end of the sampling period the samples were imported to the UK under permit in a cryogenic dry shipper $\left(-146^{\circ} \mathrm{C}\right)$ and the samples were stored at $-80^{\circ} \mathrm{C}$ until analysis.

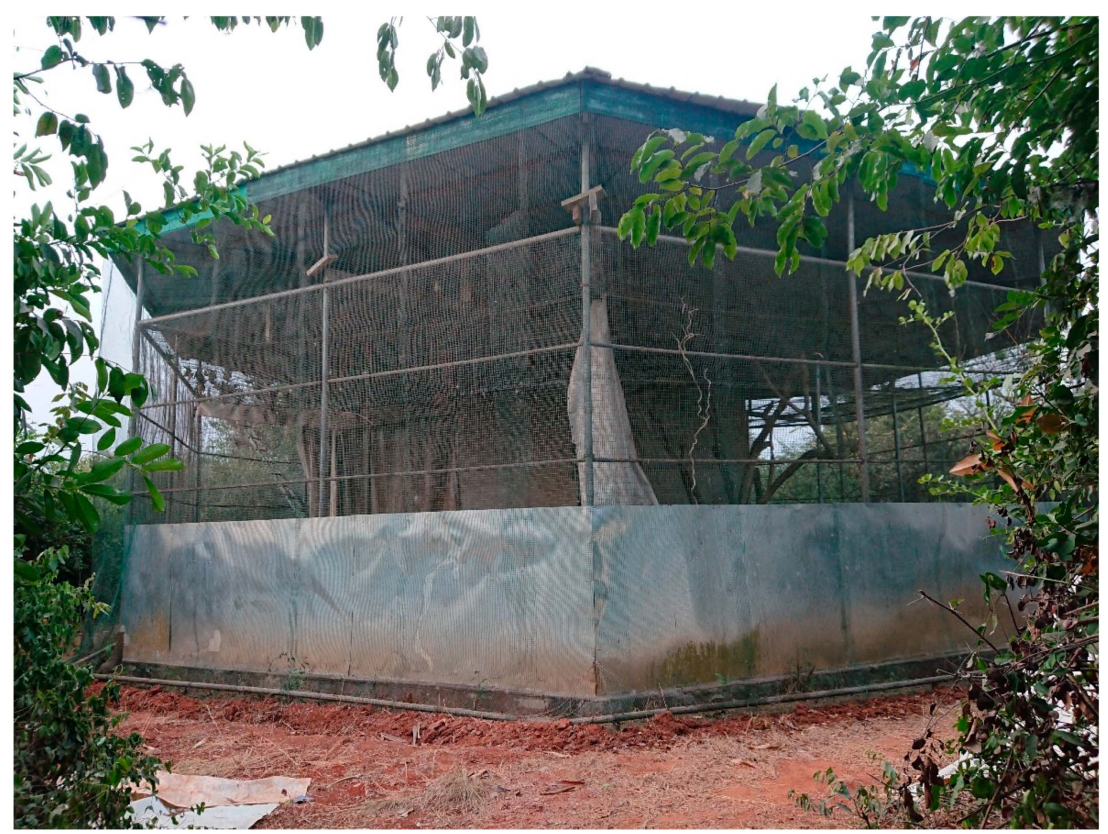

Figure 1. Cage housing the Eidolon helvum bat colony. The mesh double-walls, ground-level cladding and outer solid roof are clearly visible. Note, the bat colony can be seen roosting while hanging from the inner mesh roof towards the left side of this photograph.

Urine samples were vortexed for $30 \mathrm{~s}$ and centrifuged at $4000 \times \mathrm{g}$ for $10 \mathrm{~min}$ to obtain a cell-free supernatant. RNA was extracted from $400 \mu \mathrm{L}$ of supernatant using the MagMAX Viral RNA isolation kit (Applied Biosystems, Waltham, MA, USA) following the manufacturer's protocol with carrier RNA replaced with linear polyacrylamide (Invitrogen, Waltham, MA, USA). All samples were further treated using the TURBO DNA-free Kit (Ambion, Austin, TX, USA) following the manufacturer's instructions.

All samples were screened using pan-paramyxovirus hemi-nested RT-PCR (PARPCR) and Respirovirus-Morbillivirus-Henipavirus subgroup (RMH-PCR) using previously published primer sets [35] and modified PCR mixtures and thermocycling conditions. For the first PCR in the hemi-nested assay, we used the SuperScript III One-Step reverse transcription-PCR (RT-PCR) kit (Invitrogen, Waltham, MA, USA). The PCR mixture contained $1 \times$ reaction mix, 25 pmol of forward and reverse primers each, $10 \mathrm{nmol} \mathrm{MgSO}$, $1 \mu \mathrm{L}$ of Superscript III RT/Platinum Taq mix and $2 \mu \mathrm{L}$ aliquot of the RNA extract. Water was then added to achieve a final reaction volume of $25 \mu \mathrm{L}$. The thermocycler settings for the first reaction were: $60^{\circ} \mathrm{C}$ for $1 \mathrm{~min}, 48^{\circ} \mathrm{C}$ for $30 \mathrm{~min}, 94{ }^{\circ} \mathrm{C}$ for $2 \mathrm{~min}, 40 \times \mathrm{PCR}$ cycles $\left(94{ }^{\circ} \mathrm{C}\right.$ for $2 \mathrm{~min}, 49^{\circ} \mathrm{C}$ for $15 \mathrm{~s}, 68^{\circ} \mathrm{C}$ for $1 \mathrm{~min}$ ), $68^{\circ} \mathrm{C}$ for $5 \mathrm{~min}$ and $4{ }^{\circ} \mathrm{C}$ until the end. For the second PCR in the hemi-nested assay, we used the Roche Expand High Fidelity PCR system (Roche, Basel, Switzerland). The PCR mixture contained $1 \times$ reaction buffer 3, $25 \mathrm{pmol}$ of forward and reverse primers each, $50 \mathrm{nmol} \mathrm{of} \mathrm{MgCl}_{2}, 5 \mathrm{nmol}$ of dNTP 
mix, $1.75 \mathrm{U}$ of Expand High Fidelity Enzyme mix and $1 \mu \mathrm{L}$ aliquot of the first reaction. Water was then added to achieve a final volume of $25 \mu \mathrm{L}$. The thermocycler settings for the second reaction were: $94{ }^{\circ} \mathrm{C}$ for $2 \mathrm{~min}, 40 \times$ PCR cycles $\left(94{ }^{\circ} \mathrm{C}\right.$ for $15 \mathrm{~s}, 49^{\circ} \mathrm{C}$ for $30 \mathrm{~s}, 72{ }^{\circ} \mathrm{C}$ for $1 \mathrm{~min}), 72{ }^{\circ} \mathrm{C}$ for $5 \mathrm{~min}, 4^{\circ} \mathrm{C}$ until the end.

The PAR-PCR primer sets amplify a $530 \mathrm{bp}$ fragment of highly conserved polymerase $L$ genes. The RMH-PCR primer sets amplify a $439 \mathrm{bp}$ fragment upstream of the polymerase $L$ gene designed to be more specific for these PV genera.

PCR products were mixed with $5 \times$ DNA Loading Buffer (Qiagen, Hilden, Germany) and were electrophoresed in $2 \%(w / v)$ agarose gel followed by visualisation using GelGreen (Biotium, Fremont, CA, USA) nucleic acid stain and blue light. Positive bands of expected sizes were gel extracted using the MinElute kit (Qiagen, Hilden, Germany) and Sanger sequenced by a commercial laboratory (Eurofins Genomics, Ebersberg, Germany).

Deduced viral sequences were aligned using Geneious software v11.1.5 [36]. Sequences were then run through the Basic Local Alignment Search Tool [37] to identify the similarity with previously published sequences (Table S1).

For phylogenetic tree inference, publicly available sequences were downloaded from NCBI GenBank (Table S2) and multiple alignments made using MUSCLE [38] in program MEGA X [39]. Maximum likelihood trees were constructed using model selection GTR+I+G [40] and 1000 bootstrap iterations in program MEGA X [39].

\section{Results}

PAR- and RMH-PCR assays produced seventeen and sixty-eight amplicons, respectively, from the urine samples tested (Table 1, Figure 2). Upon alignment, nine distinct sequences were identified (Table S3), with close phylogenetic relationships between most sequences and with known PV sequences previously reported from E. helvum bats (Figures 3 and 4). Three distinct sequences, Z15-U17P, Z15-U27P and Z15-U111P (Genbank MZ393370-2) were obtained using the PAR-PCR assay and six distinct sequences, Z15-12R, Z15-U17R, Z15-U27R, Z15-U78R, Z15-U86R and Z15-U115R (Genbank MZ393364-9) were obtained using the RMH-PCR assay.

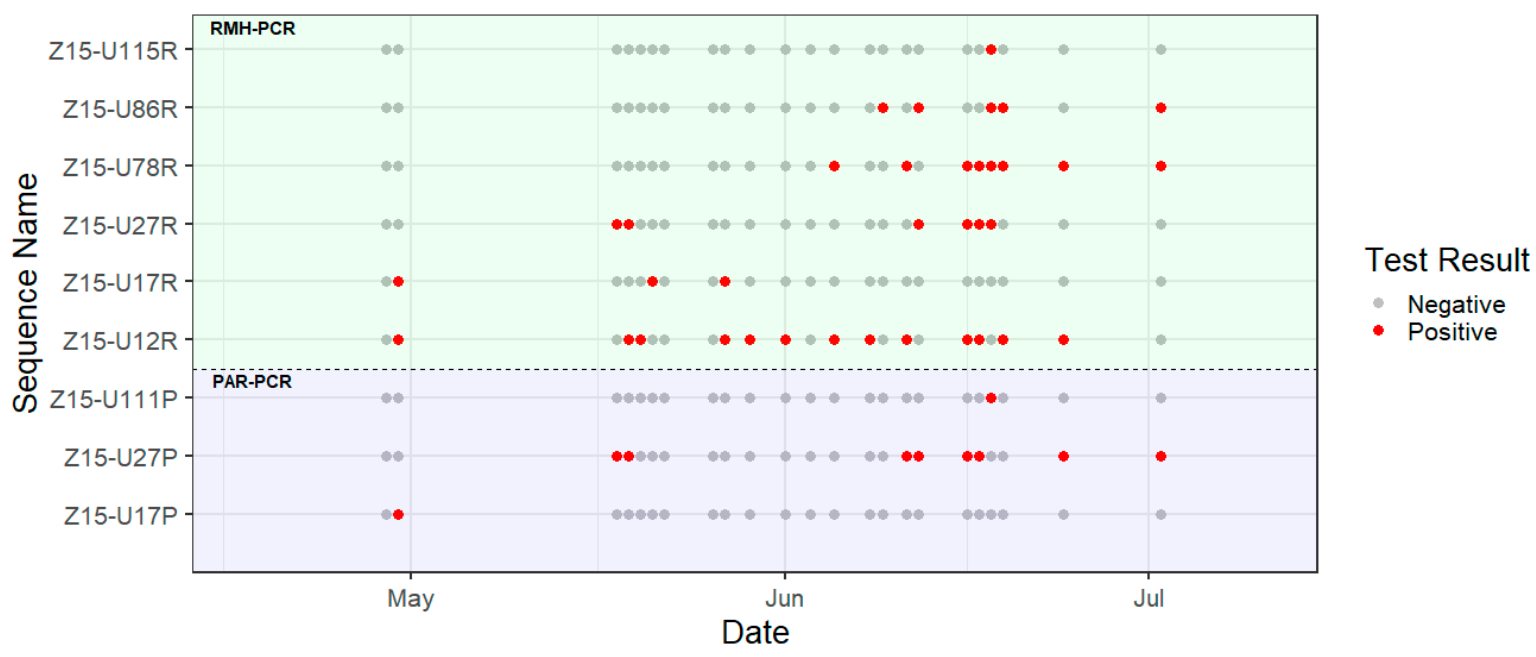

Figure 2. Timeline of amplicon sequences detected using the PAR-PCR (lower panel) and RMH-PCR assays (upper panel). The red dot denotes the positive amplicon sequence and the grey dot denotes the negative amplicon sequence detected at each time point. 
Table 1. The number of urine samples tested at each sampling time point and corresponding number of positive amplicons detected for PAR- and RMH-PCR assays.

\begin{tabular}{|c|c|c|c|}
\hline \multirow{2}{*}{ Date } & \multirow{2}{*}{ No. of Samples Tested } & \multicolumn{2}{|c|}{ No. of PCR Positive Amplicons } \\
\hline & & PAR-PCR & RMH-PCR \\
\hline $29 / 04 / 2015$ & 10 & 0 & 0 \\
\hline $30 / 04 / 2015$ & 15 & 1 & 7 \\
\hline $18 / 05 / 2015$ & 5 & 4 & 4 \\
\hline $19 / 05 / 2015$ & 5 & 1 & 3 \\
\hline $20 / 05 / 2015$ & 5 & 0 & 1 \\
\hline $21 / 05 / 2015$ & 5 & 0 & 1 \\
\hline $22 / 05 / 2015$ & 5 & 0 & 0 \\
\hline $26 / 05 / 2015$ & 3 & 0 & 0 \\
\hline $27 / 05 / 2015$ & 5 & 0 & 4 \\
\hline $29 / 05 / 2015$ & 5 & 0 & 1 \\
\hline $01 / 06 / 2015$ & 5 & 0 & 3 \\
\hline $03 / 06 / 2015$ & 5 & 0 & 0 \\
\hline $05 / 06 / 2015$ & 5 & 0 & 4 \\
\hline $08 / 06 / 2015$ & 5 & 0 & 5 \\
\hline 09/06/2015 & 5 & 0 & 4 \\
\hline $11 / 06 / 2015$ & 5 & 1 & 2 \\
\hline $12 / 06 / 2015$ & 5 & 1 & 2 \\
\hline $16 / 06 / 2015$ & 5 & 4 & 4 \\
\hline $17 / 06 / 2015$ & 5 & 2 & 5 \\
\hline $18 / 06 / 2015$ & 5 & 1 & 5 \\
\hline $19 / 06 / 2015$ & 5 & 0 & 5 \\
\hline $24 / 06 / 2015$ & 5 & 1 & 4 \\
\hline $02 / 07 / 2015$ & 5 & 1 & 4 \\
\hline
\end{tabular}

The three sequences obtained using the PAR-PCR assay were located within three distinct clades throughout the Paramyxoviridae phylogeny (Figure 3). Sequences Z15U17P and Z15-U27P showed high nucleotide identities ( $>95 \%)$ with previously detected sequences derived from E. helvum bats in Zambia [2] and Ghana [15], respectively. Sequence Z15-U17P grouped in the Henipavirus genus exhibiting $74.2 \%$ and $72.9 \%$ homology to NiV and $\mathrm{HeV}$, respectively, whilst sequence Z15-U27P grouped with other henipa-related viral sequences. Sequence Z15-U111P clustered within a phylogenetically diverse subgroup of the Pararubulavirus genus that included AchPV1 and had 98\% nucleotide identity with clones U69C/D [15] derived from Ghana. 


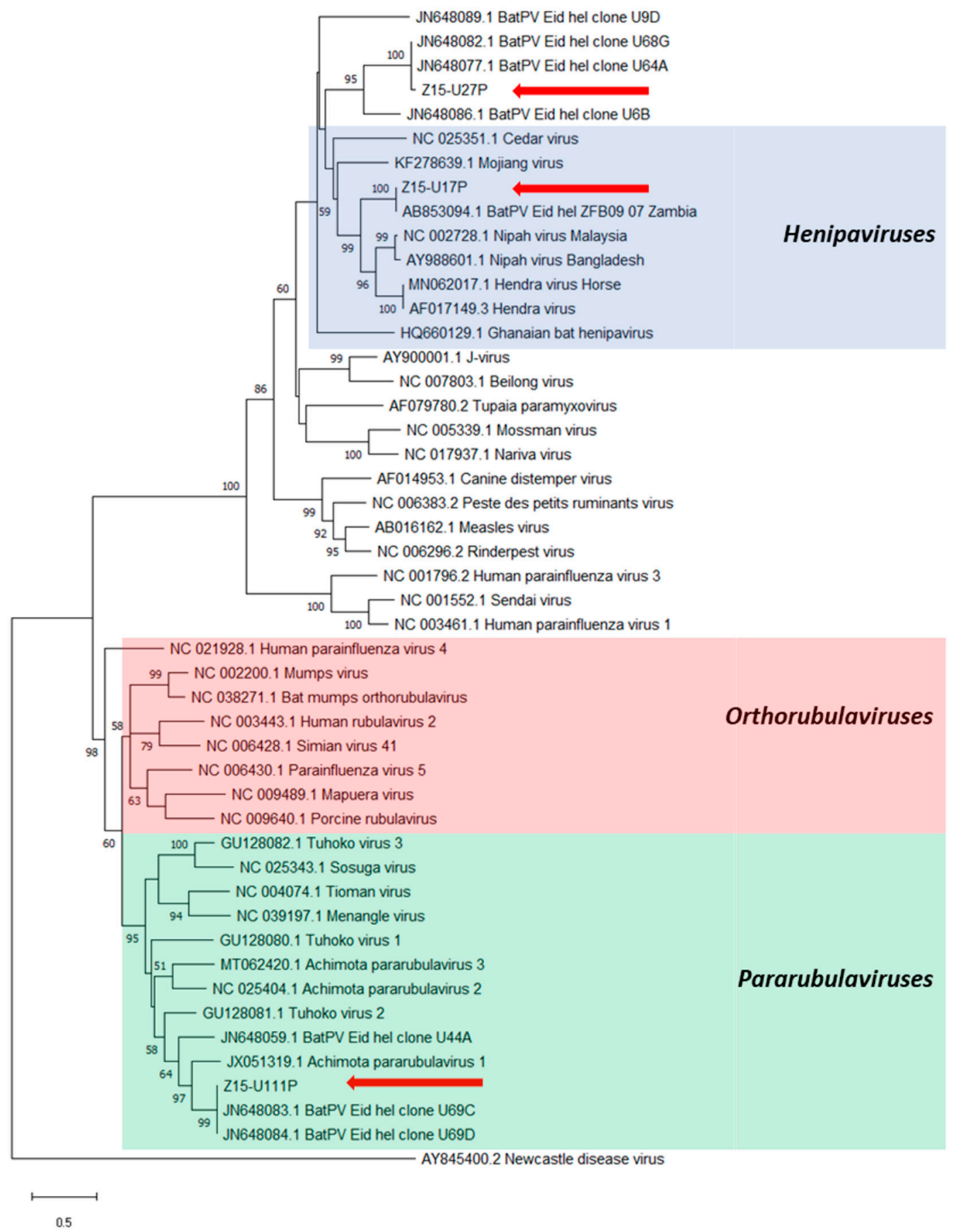

Figure 3. Phylogenetic analysis of partial $L$ gene sequences obtained after PAR-PCR on E. helvum urine samples (red arrows). Maximum likelihood tree with bootstrapping (1000 iterations) generated in MEGA X, using 530 bp alignment against publicly available paramyxovirus sequences (NCBI Genbank) and outgroup Newcastle disease virus. Bootstrap values for 1000 replicates are indicated as percentages (where $>50 \%$ ) and the number of nucleotide substitutions per site is to scale as indicated by the scale bar. 


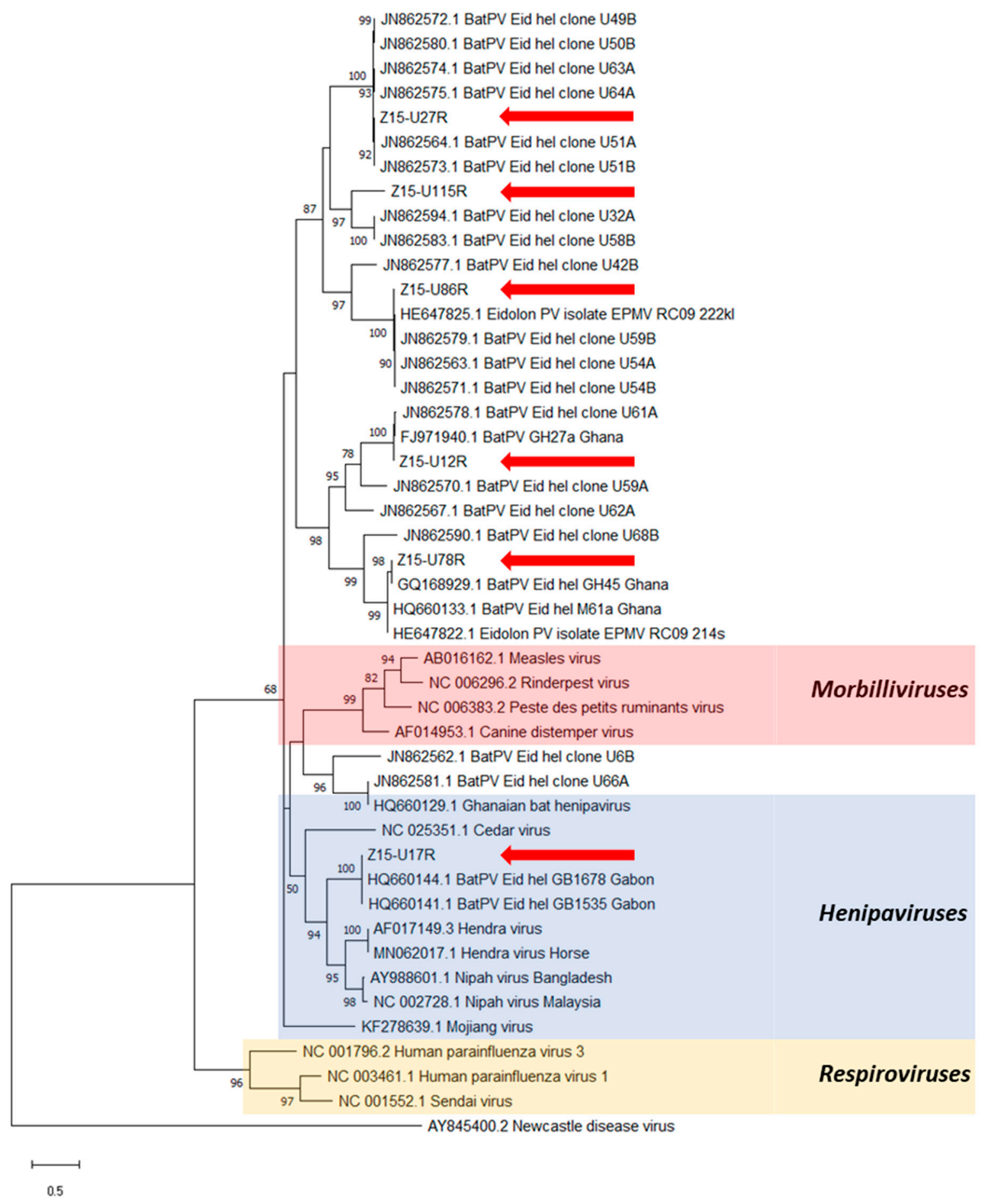

Figure 4. Phylogenetic analysis of partial $L$ gene sequences obtained after RMH-PCR on E. helvum urine samples (red arrows). Maximum likelihood tree with bootstrapping (1000 iterations) generated in MEGA X, using 439 bp alignment against publicly available paramyxovirus sequences (NCBI Genbank) and outgroup Newcastle disease virus. Bootstrap values for 1000 replicates are indicated as percentages (where $>50 \%$ ) and the number of nucleotide substitutions per site is to scale as indicated by the scale bar.

Six distinct sequences were obtained with the RMH-PCR assay and these were scattered throughout the phylogenetic tree (Figure 4). Sequence Z15-U17R was located within the Henipavirus clade, while the other sequences were in diverse subgroups phylogenetically related to the henipaviruses. All sequences showed high nucleotide identities (>95\%) with previously published sequences derived from E. helvum bats in Ghana, Gabon or 
the Republic of Congo [14,15,41], except for Z15-U115R, which is novel, having only $76 \%$ similarity to the nearest known sequences, those of clones (U58B and U32A) derived from E. helvum in Ghana [15].

Six of the nine sequences were detected during more than one sampling time point (Figure 2), with sequence Z15-U12R being the most frequently detected, in 13 out of 23 time points. Multiple sequences were most frequently observed during the mid-June time points.

\section{Discussion}

In this study, we detected the presence of multiple paramyxoviruses in our closed captive colony of E. helvum bats. The colony had been closed to new arrivals (other than births) for five years prior to the current study and the enclosure had double-mesh walls and a solid roof to prevent contact with bats or other free-living wildlife. To the best of our knowledge, this is the first report of persistence of multiple members of the Paramyxoviridae family within a small ( 115 individuals), isolated bat population.

We found a range of PVs in our captive population of E. helvum. Analysis of the $L$ gene fragments shows that the three and six distinct PV sequences detected by the PAR-PCR and RMH-PCR assays, respectively, belong to phylogenetically distinct subgroups. The six distinct and diverse sequences detected by the RMH-PCR and the pararubulavirus sequence detected using the PAR-PCR suggests that at least one henipavirus, one pararubulavirus and five unclassified PVs were simultaneously circulating in the colony. Six of nine sequences from the PAR- and RMH- PCR assays were almost identical (>95\% homology) to sequences derived from the urban population of E. helvum in Accra, from which the captive colony originated $[14,15,18]$. These results, along with the isolation of the captive colony, suggest that the captive bats naturally acquired the infection in the original free-ranging population and the viruses were subsequently maintained in captivity over the following 5 -year period. Only a small number of people are authorised to enter the bat cage, which is otherwise locked shut. This, along with the wearing of new or disinfected personal protective equipment, including coveralls and footwear, when entering the bat cage and the absence of any other bats being held in Accra Zoo reduces the likelihood of virus incursion via fomites. Although the cage construction precludes direct contact between wild and captive bats, and makes droplet transmission extremely unlikely, it cannot completely remove any possibility of aerosol transmission. While it is, therefore, possible that infection occurred subsequent to the founding of the captive colony via aerosol from wild bats or via fomites, it seems unlikely that this would be the case for such a large number of PVs. The sequences Z15-U17P, Z15-U17R, Z15-U78R and Z15-86R show great similarity to E. helvum derived sequences from Zambia, Gabon or the Republic of Congo [2,14,41]. Again, the founder bats were likely infected with these viruses at the time of capture, reinforcing previous observations of infection homogeneity across the panmictic E. helvum populations in Africa [30].

Six of the nine sequences were detected more than once during the course of the study. Some sequences were more frequently detected than others and the highest diversity of sequences was detected in the mid-June period. However, we are unable to comment on specific viral shedding patterns due to limitations in the methodology. The study was not conducted throughout the year and the sampling strategy to avoid collecting from urine pools contaminated with faeces or diluted with rainwater may have introduced a sampling bias, potentially missing urine from bats excreting virus. In addition, we did not test for the presence of PCR inhibition which may have affected virus detection. Nevertheless, the synchronous shedding of diverse PVs in pooled urine samples was detected using the same PCR assay. This could represent co-infection among individuals or could derive from multiple infected bats contributing to the same sample pool. Longitudinal studies on virus shedding in the colony and of the shedding status of individual bats are required to further determine the infection dynamics of PVs in this species. 
Due to the differences in phylogenetic trees depending on the gene/fragment amplified, it is not possible to establish relationships between sequences derived from different assays. Sequences Z15-U17P amplified using the PAR-PCR and Z15-U17R amplified by the RMH-PCR may represent different fragments from the same or different viruses. The two sequences detected in the same urine pool may be explained by one or more bats excreting two viruses. However, as both sequences phylogenetically cluster closely with the Henipavirus clade, it is also possible that they belong to a single virus. Whilst they were both initially detected during the same time point in April 2015, Z15-U17R was detected during two further time points in May 2015 using the RMH-PCR assay. If both sequences do belong to the same virus, the absence of detection in the same urine pools using the PAR-PCR assay could be attributed to PCR inhibition or differences in assay sensitivity and specificity, as previously reported [15]. To confidently identify the viruses circulating in the captive colony, successful viral isolation and full genome sequencing are required.

In this study, we detected henipavirus-like sequences in multiple samples collected over a two-month period, showing repeated excretion over time. Conventional wisdom indicates that viruses such as PVs have a short infectious period and require large population sizes to enable persistence [42]. Patterns of PV infection in mammals other than bats suggest that minimum group size, usually above 100,000 individuals, is needed for pathogen persistence in a population [42,43]. In contrast, evidence of PV persistence in our closed captive colony of E. helvum, with approximately 115 individuals, suggests that at least some PVs can persist in small, isolated populations. This is consistent with longitudinal serological monitoring of this captive colony, whereby patterns of seroconversion in captive-born bats had led us to hypothesise that PVs were persisting and circulating within the colony over 10 years [33]. Similarly, antibodies against at least one henipavirus have been detected in an isolated, free-ranging population of E. helvum comprising $<2500$ individuals on Annobón island [44]. Taken together, these findings infer that at least some bat PVs might persist within individuals with long-term continuous or intermittent excretion. Persistent latent infection with recrudescence during periods of immune suppression has been suggested for NiV in Pteropus spp. [45] and observations of apparent increased henipavirus excretion, as inferred by increased antibody detection during periods of breeding or nutritional stress in fruit bats, may be consistent with this hypothesis [31,46]. Recent models of PV transmission dynamics in bat populations using age-specific serological data indicate that population-level persistence could be reliant on within-host persistence [47]. Longitudinal paired serology-virology data and studies on bat immune responses to PV infection are required to further investigate mechanisms of PV persistence in bat populations.

Phylogenetic analyses have placed bats as tentative ancestral hosts of major mammalian PVs [14]. Additionally, sequencing of highly conserved motifs in the PV genome has shown that African rather than Asian henipavirus clades are identical to the viral ancestors [14]. Therefore, it is suggested that all henipaviruses, including $\mathrm{HeV}$ and $\mathrm{NiV}$, have evolved from a common ancestor of African origin [14]. The diversity of $L$ gene sequences, including a likely novel sequence (Z15-U115R), detected within our small captive population further support the hypothesis that bats are the natural reservoirs for PVs [14].

These findings suggest that additional diversity of PVs with zoonotic potential exists in bat populations, particularly in Africa, and the study of these viruses might help to inform the detection of future spillover events. However, increased efforts are needed to fully characterise PV diversity in African bats in order to elucidate viral infection dynamics and mechanisms of persistence in bat populations. The absence of any observed disease outbreaks or unusual mortality events in the captive bat colony supports findings from Ghana and elsewhere that PV infection does not cause clinically obvious ill health in fruit bats, e.g., [15,17-19]. It is possible, however, that infection with one or more of the PVs detected does have a more nuanced negative impact on individual fitness. Detailed histopathological and virological investigations of freshly dead bats and longitudinal studies of bats naturally or experimentally infected with different PVs are required to provide a better understanding of the impacts of infection. 
Our unique opportunity to study a small colony of captive E. helvum has found that multiple paramyxoviruses can persist over at least a 5-year period. To our knowledge, we provide the first evidence of viral persistence in an isolated population of fewer than 150 individuals. Phylogenetic analyses of detected viral sequences show that a great diversity of paramyxoviruses was present in the colony, including one potentially novel viral sequence. Though we are not able to confidently report on viral transmission or dynamics, further studies to fully characterise these paramyxoviruses and longitudinal studies would improve our understanding of these. Close relationships between some sequences and known human pathogens in the Henipavirus and Pararubulavirus genera circulating in free-living E. helvum was observed. Eidolon helvum forms large roosts in both rural and urban areas across much of Africa and is widely hunted [29,48], presenting multiple opportunities for human exposure to bat paramyxoviruses.

Supplementary Materials: The following are available online at https:/ / www.mdpi.com/article/10 $.3390 / v 13081659 /$ s1, Table S1: Top BLAST results from the submission of the consensus sequence of the $L$ gene, Table S2: Information of the virus sequences used for phylogenetic analyses downloaded from GenBank (NCBI), Table S3: Nucleotide sequences detected using PCR.

Author Contributions: L.G.: methodology, data curation, formal analysis, project administration, supervision, investigation, writing-original draft preparation, writing-review and editing, visualisation; M.P.R.: methodology, data curation, formal analysis, investigation, writing — original draft preparation, writing - review and editing; J.K.: methodology, investigation, writing-review and editing; O.R.: funding acquisition, writing-review and editing; R.D.S.-I.: methodology, project administration, resources, supervision, investigation, writing-review and editing, visualisation; J.L.N.W.: conceptualisation, methodology, funding acquisition, supervision, writing-review and editing, visualisation; A.A.C.: conceptualisation, methodology, funding acquisition, resources, supervision, writing - review and editing, visualisation. All authors have read and agreed to the published version of the manuscript.

Funding: This research was funded by Research England, the Royal Veterinary College, the Medical Research Council (grant number MR/P025226/1) and the Defense Advanced Research Projects Agency (DARPA) administered through Cooperative Agreement \#D18AC00031-PREEMPT. JLNW and OR are funded by The Alborada Trust. AAC was part-funded by a Royal Society Wolfson Research Merit award.

Institutional Review Board Statement: The study was conducted according to UK legislation and the Zoological Society of London's policy on the Use of Animals in Research. All fieldwork was undertaken under permits granted by the Wildlife Division of the Forestry Commission of Ghana with ethical approval from the Ethics Committee of the Zoological Society of London (protocol code WLE/067 and IOZ12).

Informed Consent Statement: Not applicable.

Data Availability Statement: Data is contained within the article or Supplementary Materials.

Acknowledgments: We thank the Forestry Commission of Ghana for permitting the collection of the samples; Aaron Morris, for generating Figure 2; and Chris Yesson, Institute of Zoology, for his support on generating the phylogenetic trees used in Figures 3 and 4. Louise Gibson took the photograph used for Figure 1.

Conflicts of Interest: The authors declare no conflict of interest.

\section{References}

1. Jones, K.E.; Patel, N.G.; Levy, M.A.; Storeygard, A.; Balk, D.; Gittleman, J.L.; Daszak, P. Global trends in emerging infectious diseases. Nature 2008, 451, 990-993. [CrossRef]

2. Muleya, W.; Sasaki, M.; Orba, Y.; Ishii, A.; Thomas, Y.; Nakagawa, E.; Ogawa, H.; Hang'ombe, B.; Namangala, B.; Mweene, A.; et al. Molecular epidemiology of paramyxoviruses in Frugivorous Eidolon helvum bats in Zambia. J. Vet. Med. Sci. 2014, 76, 611-614. [CrossRef] [PubMed]

3. Suu-Ire, R.; Begeman, L.; Banyard, A.C.; Breed, A.C.; Drosten, C.; Eggerbauer, E.; Freuling, C.M.; Gibson, L.; Goharriz, H.; Horton, D.L.; et al. Pathogenesis of bat rabies in a natural reservoir: Comparative susceptibility of the straw-colored fruit bat (Eidolon helvum) to three strains of Lagos bat virus. PLoS Negl. Trop. Dis. 2018, 12, e0006311. [CrossRef] [PubMed] 
4. $\quad$ Luis, A.D.; Hayman, D.T.S.; O'shea, T.J.; Cryan, P.M.; Gilbert, A.T.; Pulliam, J.R.C.; Mills, J.N.; Willis, C.K.R.; Timonin, M.E.; Cunningham, A.A.; et al. A comparison of bats and rodents as reservoirs of zoonotic viruses: Are bats special? Proc. Biol. Sci. 2013, 280, 20122753. [CrossRef]

5. Wong, S.; Lau, S.; Woo, P.; Yuen, K.Y. Bats as a continuing source of emerging infections in humans. Rev. Med. Virol. 2007, 17, 67-91. [CrossRef]

6. $\quad$ Luis, A.D.; O'Shea, T.J.; Hayman, D.T.S.; Wood, J.L.N.; Cunningham, A.A.; Gilbert, A.T.; Mills, J.N.; Webb, C.T. Network analysis of host-virus communities in bats and rodents reveals determinants of cross-species transmission. Ecol. Lett. 2015, 18, 1153-1162. [CrossRef]

7. O'Shea, T.J.; Cryan, P.M.; Cunningham, A.A.; Fooks, A.R.; Hayman, D.T.S.; Luis, A.D.; Peel, A.J.; Plowright, R.K.; Wood, J.L.N. Bat flight and zoonotic viruses. Emerg. Infect. Dis. 2014, 20, 741-745. [CrossRef]

8. Murray, K.; Rogers, R.; Selvey, L.; Selleck, P.; Hyatt, A.; Gould, A.; Gleeson, L.; Hooper, P.; Westbury, H. A novel morbillivirus pneumonia of horses and its transmission to humans. Emerg. Infect. Dis. 1995, 1, 31-33. [CrossRef] [PubMed]

9. Smith, I.; Broos, A.; de Jong, C.; Zeddeman, A.; Smith, C.; Smith, G.; Moore, F.; Barr, J.; Crameri, G.; Marsh, G.; et al. Identifying hendra virus diversity in pteropid bats. PLoS ONE 2011, 6, e25275. [CrossRef] [PubMed]

10. Chua, K.B. Nipah virus: A recently emergent deadly paramyxovirus. Science 2000, 288, 1432-1435. [CrossRef] [PubMed]

11. Hsu, V.P.; Hossain, M.J.; Parashar, U.D.; Ali, M.M.; Ksiazek, T.G.; Kuzmin, I.; Niezgoda, M.; Rupprecht, C.; Bresee, J.; Breiman, R.F. Nipah virus encephalitis reemergence, Bangladesh. Emerg. Infect. Dis. 2004, 10, 2082-2087. [CrossRef] [PubMed]

12. Luby, S.P.; Rahman, M.; Hossain, M.J.; Blum, L.S.; Husain, M.M.; Gurley, E.; Khan, R.; Ahmed, B.N.; Rahman, S.; Nahar, N.; et al. Foodborne transmission of Nipah virus, Bangladesh. Emerg. Infect. Dis. 2006, 12, 1888-1894. [CrossRef] [PubMed]

13. Ksiazek, T.G.; Rota, P.A.; Rollin, P.E. A review of Nipah and Hendra viruses with an historical aside. Virus Res. 2011, 162, 173-183. [CrossRef] [PubMed]

14. Drexler, J.F.; Corman, V.M.; Müller, M.A.; Maganga, G.D.; Vallo, P.; Binger, T.; Gloza-Rausch, F.; Rasche, A.; Yordanov, S.; Seebens, A.; et al. Bats host major mammalian paramyxoviruses. Nat. Commun. 2012, 3, 796. [CrossRef]

15. Baker, K.S.; Todd, S.; Marsh, G.; Fernandez-Loras, A.; Suu-Ire, R.; Wood, J.L.N.; Wang, L.F.; Murcia, P.R.; Cunningham, A.A. Co-circulation of diverse paramyxoviruses in an urban African fruit bat population. J. Gen. Virol. 2012, 93, 850-856. [CrossRef]

16. Mortlock, M.; Kuzmin, I.V.; Weyer, J.; Gilbert, A.T.; Agwanda, B.; Rupprecht, C.E.; Nel, L.H.; Kearney, T.; Malekani, J.M.; Markotter, W. Novel paramyxoviruses in bats from Sub-Saharan Africa, 2007-2012. Emerg. Infect. Dis. 2015, 21, 1840-1843. [CrossRef] [PubMed]

17. Barr, J.; Smith, C.; Smith, I.; De Jong, C.; Todd, S.; Melville, D.; Broos, A.; Crameri, S.; Haining, J.; Marsh, G.; et al. Isolation of multiple novel paramyxoviruses from pteropid bat urine. J. Gen. Virol. 2015, 96, 24-29. [CrossRef] [PubMed]

18. Drexler, J.F.; Corman, V.M.; Gloza-Rausch, F.; Seebens, A.; Annan, A.; Ipsen, A.; Kruppa, T.; Müller, M.A.; Kalko, E.K.V.; Adu-Sarkodie, Y.; et al. Henipavirus RNA in African bats. PLoS ONE 2009, 4, e6367. [CrossRef]

19. Baker, K.S.; Todd, S.; Marsh, G.A.; Crameri, G.; Barr, J.; Kamins, A.O.; Peel, A.J.; Yu, M.; Hayman, D.T.S.; Nadjm, B.; et al. Novel, Potentially Zoonotic Paramyxoviruses from the African Straw-Colored Fruit Bat Eidolon helvum. J. Virol. 2013, 87, 1348-1358. [CrossRef]

20. Hayman, D.T.S.; Suu-Ire, R.; Breed, A.C.; McEachern, J.A.; Wang, L.; Wood, J.L.N.; Cunningham, A.A. Evidence of henipavirus infection in West African fruit bats. PLoS ONE 2008, 3, e2739. [CrossRef]

21. Voigt, K.; Hoffmann, M.; Drexler, J.F.; Müller, M.A.; Drosten, C.; Herrler, G.; Krüger, N. Fusogenicity of the Ghana Virus (Henipavirus: Ghanaian bat henipavirus) Fusion Protein is Controlled by the Cytoplasmic Domain of the Attachment Glycoprotein. Viruses 2019, 11, 800. [CrossRef]

22. Agarwala, R.; Barrett, T.; Beck, J.; Benson, D.A.; Bollin, C.; Bolton, E.; Bourexis, D.; Brister, J.R.; Bryant, S.H.; Canese, K.; et al. Database resources of the National Center for Biotechnology Information. Nucleic Acids Res. 2018, 46, D8-D13. [CrossRef]

23. Pernet, O.; Schneider, B.S.; Beaty, S.M.; Lebreton, M.; Yun, T.E.; Park, A.; Zachariah, T.T.; Bowden, T.A.; Hitchens, P.; Ramirez, C.M.; et al. Evidence for henipavirus spillover into human populations in Africa. Nat. Commun. 2014, 5, 5342. [CrossRef] [PubMed]

24. Philbey, A.W.; Kirkland, P.D.; Ross, A.D.; Davis, R.J.; Gleeson, A.B.; Love, R.J.; Daniels, P.W.; Gould, A.R.; Hyatt, A.D. An apparently new virus (family Paramyxoviridae) infectious for pigs, humans, and fruit bats. Emerg. Infect. Dis. 1998, 4, $269-271$. [CrossRef]

25. Chua, K.B.; Wang, L.F.; Lam, S.K.; Crameri, G.; Yu, M.; Wise, T.; Boyle, D.; Hyatt, A.D.; Eaton, B.T. Tioman virus, a novel paramyxovirus isolated from fruit bats in Malaysia. Virology 2001, 283, 215-229. [CrossRef]

26. Lau, S.K.P.; Woo, P.C.Y.; Wong, B.H.L.; Wong, A.Y.P.; Tsoi, H.W.; Wang, M.; Lee, P.; Xu, H.; Poon, R.W.S.; Guo, R.; et al. Identification and complete genome analysis of three novel paramyxoviruses, Tuhoko virus 1, 2 and 3, in fruit bats from China. Virology 2010, 404, 106-116. [CrossRef]

27. Baker, K.S.; Tachedjian, M.; Barr, J.; Marsh, G.A.; Todd, S.; Crameri, G.; Crameri, S.; Smith, I.; Holmes, C.E.G.; Suu-Ire, R.; et al. Achimota Pararubulavirus 3: A New Bat-Derived Paramyxovirus of the Genus Pararubulavirus. Viruses 2020, 12, 1236. [CrossRef] [PubMed]

28. Barr, J.; Todd, S.; Crameri, G.; Foord, A.; Marsh, G.; Frazer, L.; Payne, J.; Harper, J.; Baker, K.S.; Cunningham, A.A.; et al. Animal infection studies of two recently discovered African bat paramyxoviruses, Achimota 1 and Achimota 2. Sci. Rep. 2018, 8, 12744. [CrossRef] 
29. Mickleburgh, S.; Waylen, K.; Racey, P. Bats as bushmeat: A global review. ORYX 2009, 43, 217-234. [CrossRef]

30. Peel, A.J.; Sargan, D.R.; Baker, K.S.; Hayman, D.T.S.; Barr, J.A.; Crameri, G.; Suu-Ire, R.; Broder, C.C.; Lembo, T.; Wang, L.F.; et al. Continent-wide panmixia of an African fruit bat facilitates transmission of potentially zoonotic viruses. Nat. Commun. 2013, 4, 2770. [CrossRef] [PubMed]

31. Baker, K.S.; Suu-Ire, R.; Barr, J.; Hayman, D.T.S.; Broder, C.C.; Horton, D.L.; Durrant, C.; Murcia, P.R.; Cunningham, A.A.; Wood, J.L.N. Viral antibody dynamics in a chiropteran host. J. Anim. Ecol. 2014, 83, 415-428. [CrossRef]

32. Peel, A.J.; McKinley, T.J.; Baker, K.S.; Barr, J.A.; Crameri, G.; Hayman, D.T.S.; Feng, Y.R.; Broder, C.C.; Wang, L.F.; Cunningham, A.A.; et al. Use of cross-reactive serological assays for detecting novel pathogens in wildlife: Assessing an appropriate cutoff for henipavirus assays in African bats. J. Virol. Methods 2013, 193, 295-303. [CrossRef]

33. Glennon, E.E.; Becker, D.J.; Peel, A.J.; Garnier, R.; Suu-Ire, R.D.; Gibson, L.; Hayman, D.T.S.; Wood, J.L.N.; Cunningham, A.A.; Plowright, R.K.; et al. What is stirring in the reservoir? Modelling mechanisms of henipavirus circulation in fruit bat hosts. Philos. Trans. R. Soc. B Biol. Sci. 2019, 374, 20190021. [CrossRef]

34. Edson, D.; Field, H.; McMichael, L.; Vidgen, M.; Goldspink, L.; Broos, A.; Melville, D.; Kristoffersen, J.; De Jong, C.; McLaughlin, A.; et al. Routes of hendra virus excretion in naturally-infected flying-foxes: Implications for viral transmission and spillover risk. PLoS ONE 2015, 10, e0140670. [CrossRef] [PubMed]

35. Tong, S.; Chern, S.W.W.; Li, Y.; Pallansch, M.A.; Anderson, L.J. Sensitive and broadly reactive reverse transcription-PCR assays to detect novel paramyxoviruses. J. Clin. Microbiol. 2008, 46, 2652-2658. [CrossRef]

36. Kearse, M.; Moir, R.; Wilson, A.; Stones-Havas, S.; Cheung, M.; Sturrock, S.; Buxton, S.; Cooper, A.; Markowitz, S.; Duran, C.; et al. Geneious Basic: An integrated and extendable desktop software platform for the organization and analysis of sequence data. Bioinformatics 2012, 28, 1647-1649. [CrossRef] [PubMed]

37. NCBI Nucleotide BLAST: Search Nucleotide Databases Using a Nucleotide Query. Basic Local Alignment Search Tool. 2015. Available online: https:/ / blast.ncbi.nlm.nih.gov/Blast.cgi (accessed on 15 June 2021).

38. Edgar, R.C. MUSCLE: Multiple sequence alignment with high accuracy and high throughput. Nucleic Acids Res. 2004, 32, 1792-1797. [CrossRef]

39. Kumar, S.; Stecher, G.; Li, M.; Knyaz, C.; Tamura, K. MEGA X: Molecular evolutionary genetics analysis across computing platforms. Mol. Biol. Evol. 2018, 35, 1547-1549. [CrossRef] [PubMed]

40. Abadi, S.; Azouri, D.; Pupko, T.; Mayrose, I. Model selection may not be a mandatory step for phylogeny reconstruction. Nat. Commun. 2019, 10, 1-11. [CrossRef]

41. Weiss, S.; Nowak, K.; Fahr, J.; Wibbelt, G.; Mombouli, J.V.; Parra, H.J.; Wolfe, N.D.; Schneider, B.S.; Leendertz, F.H. Henipavirusrelated sequences in fruit bat bushmeat, Republic of Congo. Emerg. Infect. Dis. 2012, 18, 1536-1537. [CrossRef]

42. Pomeroy, L.W.; Bjørnstad, O.N.; Holmes, E.C. The evolutionary and epidemiological dynamics of the paramyxoviridae. J. Mol. Evol. 2008, 66, 98-106. [CrossRef] [PubMed]

43. Bartlett, M.S. Measles Periodicity and Community Size. J. R. Stat. Soc. Ser. A 1957, 120, 48-60. [CrossRef]

44. Peel, A.J.; Baker, K.S.; Crameri, G.; Barr, J.A.; Hayman, D.T.S.; Wright, E.; Broder, C.C.; Fernández-Loras, A.; Fooks, A.R.; Wang, L.F.; et al. Henipavirus neutralising antibodies in an isolated island population of African fruit bats. PLoS ONE 2012, 7, e30346. [CrossRef] [PubMed]

45. Rahman, S.A.; Hassan, S.S.; Olival, K.J.; Mohamed, M.; Chang, L.Y.; Hassan, L.; Saad, N.M.; Shohaimi, S.A.; Mamat, Z.C.; Naim, M.S.; et al. Characterization of Nipah virus from naturally infected Pteropus vampyrus bats, Malaysia. Emerg. Infect. Dis. 2010, 16, 1990-1993. [CrossRef]

46. Plowright, R.K.; Field, H.E.; Smith, C.; Divljan, A.; Palmer, C.; Tabor, G.; Daszak, P.; Foley, J.E. Reproduction and nutritional stress are risk factors for Hendra virus infection in little red flying foxes (Pteropus scapulatus). Proc. R. Soc. B Biol. Sci. 2008, 275, 861-869. [CrossRef]

47. Peel, A.J.; Baker, K.S.; Hayman, D.T.S.; Broder, C.C.; Cunningham, A.A.; Fooks, A.R.; Garnier, R.; Wood, J.L.N.; Restif, O. Support for viral persistence in bats from age-specific serology and models of maternal immunity. Sci. Rep. 2018, 3859, 1-11. [CrossRef]

48. Kamins, A.O.; Restif, O.; Ntiamoa-Baidu, Y.; Suu-Ire, R.; Hayman, D.T.S.; Cunningham, A.A.; Wood, J.L.N.; Rowcliffe, J.M. Uncovering the fruit bat bushmeat commodity chain and the true extent of fruit bat hunting in Ghana, West Africa. Biol. Conserv. 2011, 144, 3000-3008. [CrossRef] 